\title{
Strong enhancement of the lanthanide-centred luminescence in complexes with 4-alkylated $2,2^{\prime} ; \mathbf{6}^{\prime}, \mathbf{2}^{\prime \prime}$-terpyridines $\dagger^{\dagger}$
}

\author{
Hans-Ruedi Mürner, ${ }^{a}$ Emilie Chassat, ${ }^{b}$ Randolph P. Thummel ${ }^{b}$ and Jean-Claude G. Bünzli *a \\ ${ }^{a}$ Institute of Inorganic and Analytical Chemistry, BCH, University of Lausanne, \\ CH-1015 Lausanne, Switzerland.E-mail: jean-claude.bunzli@icma.unil.ch \\ ${ }^{b}$ Department of Chemistry, University of Houston, Houston, TX 77204, USA
}

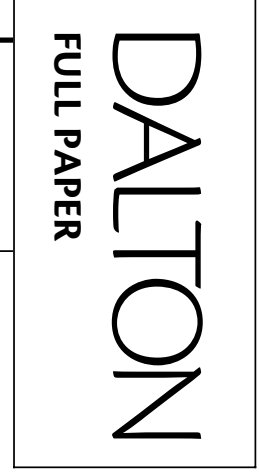

Received 4th May 2000, Accepted 28th June 2000

Published on the Web 24th July 2000

\begin{abstract}
The stability and photophysical properties of trivalent lanthanide complexes with $2,2^{\prime} ; 6^{\prime}, 2^{\prime \prime}$-terpyridines substituted in the 4 position $\left(\mathrm{L}^{1}, t\right.$-butyl; $\mathrm{L}^{2}$, ethyl) have been compared to those with the unsubstituted ligand terpy. The stability constants $\log \beta_{3}$ of complexes with $\mathrm{L}^{1}$ and terpy are similar and reflect a preference for the harder heavier members of the series. Cyclic voltammetry of the $\left[\mathrm{Eu}(\mathrm{L})_{3}\right]\left[\mathrm{ClO}_{4}\right]_{3}$ complexes show a considerable cathodic shift of the $\mathrm{Eu}^{\mathrm{III}}-\mathrm{Eu}^{\mathrm{II}}$ reduction potential on going from terpy to $\mathrm{L}^{2}$ and $\mathrm{L}^{1}$. The energy of the LMCT states, indirectly determined from the half peak potentials for ligand oxidation and europium(III) reduction, is too high to allow an effective non-radiative deactivation by this pathway. Complexes of the substituted ligands $\left[\mathrm{Ln}\left(\mathrm{L}^{i}\right)_{3}\right]\left[\mathrm{ClO}_{4}\right]_{3}(\mathrm{Ln}=\mathrm{Eu}$ or $\mathrm{Tb})$ show a substantial increase in the quantum yields of the metal-centred luminescence in acetonitrile solution compared to the terpy reference systems: $Q^{\mathrm{Eu}}=0.10\left(\mathrm{~L}^{1}\right), 0.11\left(\mathrm{~L}^{2}\right) v s .0 .013$ (terpy), and $Q^{\mathrm{Tb}}=0.67\left(\mathrm{~L}^{1}\right), 0.34\left(\mathrm{~L}^{2}\right) v s .0 .047$ (terpy). The main factor responsible for this enhancement arises from a facilitated intersystem crossing in $\mathrm{L}^{1}, \mathrm{~L}^{2}$ and in their complexes, as demonstrated by the ratio of the fluorescence and phosphorescence intensity of both the "free" ligands and their lanthanum(III) tris complexes. This effect is tentatively assigned to the electron donating substituents in the 4 position affecting the mixing of energetically close singlet and triplet ligand states.
\end{abstract}

\section{Introduction}

Recent applications of lanthanide-containing luminescent stains for the analysis of biomedical materials, ${ }^{1}$ e.g. fluoroimmunoassays, ${ }^{2,3}$ or systems in which lanthanide reporter groups signal changes in the concentration of an analyte $\left(\mathrm{H}^{+}, \mathrm{O}_{2}\right.$, $\left(\mathrm{Cl}^{-}\right),{ }^{4}$ have prompted chemists to search for highly luminescent systems incorporating trivalent $4 \mathrm{f}$ ions. Enhancing the sensitivity of such bioassays translates in maximising the population of the metal-centred emissive state and minimising the various non-radiative deactivation pathways, a real challenge in view of the forbidden nature of the $\mathrm{f}-\mathrm{f}$ transitions. Excitation therefore usually relies on energy transfer from ligands surrounding the lanthanide ion (antenna effect). ${ }^{5}$ Crucial for energy transfer is the energy of the lowest ligand-centred triplet state, ${ }^{6}$ but the overall quantum yield of lanthanide-centred luminescence is the sum of many other energy transfer, emission and nonradiative deexcitation processes so that small alterations in the molecular structure can lead to a drastically different behaviour. ${ }^{7-9}$ In the case of europium(III) compounds, additional deactivation pathways are opened by low lying ligandto-metal charge transfer (LMCT) states. ${ }^{10-12}$ Recently we have reported on the lowering of the LMCT state in going from $\left[\mathrm{Eu}(\mathrm{mbzimpy})\left(\mathrm{NO}_{3}\right)_{3}(\mathrm{MeOH})\right]$ to $\left[\mathrm{Eu}(\mathrm{mbzimpy})_{3}\right]^{3+}(\mathrm{mbzimpy}:$ 2,6-bis(1-methylbenzimidazol-2-yl)pyridine $)^{13}$ which is responsible for the observed dramatic decrease in the absolute quantum yield of the metal-centred luminescence $\left(Q^{\mathrm{Eu}}=0.028 v s\right.$. $\left.8.2 \times 10^{-7}\right)$. To further our understanding of the factors influencing the sensitisation of lanthanide luminescence, we have undertaken a study on triple helical complexes with derivatives of $2,2^{\prime} ; 6^{\prime}, 2^{\prime \prime}$-terpyridine (terpy) bearing substituents on the $4,4^{\prime}$ and $4^{\prime \prime}$ positions $\left(\mathrm{L}^{1}, t\right.$-butyl; $\mathrm{L}^{2}$, ethyl). We investigated both the stability of the $\left[\operatorname{Ln}(\mathrm{L})_{3}\right]^{3+}$ entities $\left(\mathrm{L}=\right.$ terpy or $\left.\mathrm{L}^{1}\right)$ in acetonitrile

$\uparrow$ Electronic supplementary information (ESI) available: emission and excitation spectra at room temperature. See http://www.rsc.org/ suppdata/dt/b0/b003577g/ and their photophysical properties $\left(\mathrm{L}=\right.$ terpy, $\mathrm{L}^{1}$ or $\left.\mathrm{L}^{2}\right)$. The results detailed below show that here the LMCT state plays a minor role in the deactivation of $\mathrm{Eu}^{\mathrm{III}}$-containing compounds. Moreover, we observe that introducing alkyl substituents in the 4 position of the pyridine rings leads to an impressive enhancement of both $\mathrm{Tb}$ - and Eu-centred luminescence. We discuss different hypotheses to account for this surprising effect.

\section{Results and discussion}

\section{Stability constants}

In an attempt to quantify the influence of the bulky $t$-butyl groups on the complexation ability with $\mathrm{Ln}^{\mathrm{III}}$, we have measured the stability constants of terpy and $\mathrm{L}^{1}$ with three representative light, mid-range and heavy lanthanides. To the best of our knowledge, no stability constants for $\left[\operatorname{Ln}(\text { terpy) }]_{3}\right]^{3+}$ complexes are reported in the literature. This is probably due to problems with the formation of conformational isomers resulting from partial decomplexation of one or two pyridine rings, first evidenced by luminescence and NMR techniques in acetonitrile solutions of the europium(III) complex. ${ }^{14}$ Partial decomplexation of terpy leads to bidentate (cis-trans, cf. Scheme 1) or monodentate (trans-trans) instead of tridentate (cis-cis) binding modes. In solution the neutral ligand adopts almost exclusively the trans-trans conformation with the exception of polar solvents, where cisoid arrangements can be stabilised by intermolecular hydrogen bonds. ${ }^{15}$ However, Mallet et al. ${ }^{16}$ have shown that solutions of $\left[\mathrm{Eu}(\text { terpy })_{3}\right]\left[\mathrm{ClO}_{4}\right]_{3}$ in anhydrous acetonitrile give rise to only one set of ${ }^{1} \mathrm{H}$ NMR signals, indicative of a large predominance of the tridentate cis-cis conformation. Upon addition of increasing amounts of water they observed that bidentate and monodentate terpy conformations become more and more important. We conclude from these reports that under anhydrous conditions the formation of conformational isomers of terpy should strongly be 
Table 1 Stability constants of $\left[\operatorname{Ln}(\text { terpy })_{n}\right]^{3+}$ and $\left[\operatorname{Ln}\left(\mathrm{L}^{1}\right)_{n}\right]^{3+}$ complexes determined by spectrophotometric titration at $20{ }^{\circ} \mathrm{C}$ in anhydrous MeCN with $0.1 \mathrm{M} \mathrm{Et}_{4} \mathrm{NClO}_{4}$

\begin{tabular}{|c|c|c|c|c|c|c|c|c|}
\hline \multirow[b]{2}{*}{ Ln } & \multicolumn{4}{|l|}{ terpy } & \multicolumn{4}{|l|}{$\mathrm{L}^{1}$} \\
\hline & $\log K_{1}$ & $\log K_{2}$ & $\log K_{3}$ & $\log \beta_{3}$ & $\log K_{1}$ & $\log K_{2}$ & $\log K_{3}$ & $\log \beta_{3}$ \\
\hline $\mathrm{Lu}$ & $7.5 \pm 0.1$ & $7.2 \pm 0.2$ & $5.4 \pm 0.3$ & $20.1 \pm 0.4$ & $8.7 \pm 0.5$ & $6.7 \pm 0.6$ & $5.4 \pm 0.6$ & $20.8 \pm 1.0$ \\
\hline $\mathrm{Eu}$ & $7.9 \pm 0.5$ & $5.5 \pm 0.5$ & $5.0 \pm 0.5$ & $18.4 \pm 0.9$ & $9.6 \pm 0.1$ & $\begin{array}{l}5.7 \pm 0.2 \\
5.3 \pm 0.8^{a}\end{array}$ & $\begin{array}{l}3.8 \pm 0.3 \\
2.8 \pm 0.4^{a}\end{array}$ & $19.1 \pm 0.4$ \\
\hline $\mathrm{La}$ & $7.7 \pm 0.2$ & $5.8 \pm 0.3$ & $4.8 \pm 0.4$ & $18.3 \pm 0.5$ & $7.6 \pm 0.5$ & $\begin{array}{l}6.4 \pm 0.7 \\
4.7 \pm 0.7^{b}\end{array}$ & $\begin{array}{l}4.4 \pm 0.7 \\
3.1 \pm 0.5^{b}\end{array}$ & $18.4 \pm 1.1$ \\
\hline
\end{tabular}<smiles>[R]c1ccnc(-c2cc([R])cc(-c3cc([R])cc(-c4cc([R])ccn4)n3)n2)c1</smiles>

$$
\begin{array}{ll}
R=H & \text { terpy } \\
R=\text { tert-butyl } & L^{1} \\
R=\text { ethyl } & L^{2}
\end{array}
$$

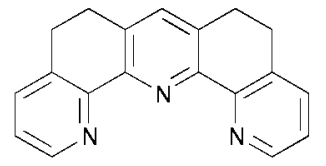

dmterpy

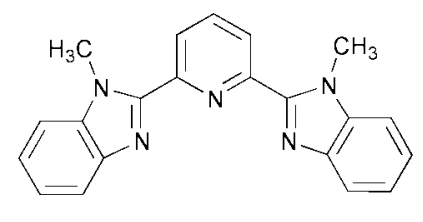

mbzimpy
Scheme 1

disfavoured. Consequently, only co-ordinated tridentate $c i s$-cis terpy will be considered in the models used to fit our experimental data.

Spectrophotometric titrations of terpy and $\mathrm{L}^{1}$ by $\mathrm{La}\left(\mathrm{CF}_{3}\right.$ $\left.\mathrm{SO}_{3}\right)_{3}, \mathrm{Eu}\left(\mathrm{ClO}_{4}\right)_{3}$ and $\mathrm{Lu}\left(\mathrm{ClO}_{4}\right)_{3}$ in anhydrous acetonitrile were carried out under a controlled dry nitrogen atmosphere in a glove box. To minimise decomplexation, all reagents were vigorously dried before use. The titration data were treated by evolving factor analysis and fitted by eqns. (1)-(3).

$$
\begin{gathered}
\mathrm{Ln}^{3+}+\mathrm{L} \rightleftharpoons[\operatorname{Ln}(\mathrm{L})]^{3+} \log K_{1} \\
{[\operatorname{Ln}(\mathrm{L})]^{3+}+\mathrm{L} \rightleftharpoons\left[\operatorname{Ln}(\mathrm{L})_{2}\right]^{3+} \log K_{2}} \\
{\left[\operatorname{Ln}(\mathrm{L})_{2}\right]^{3+}+\mathrm{L} \rightleftharpoons\left[\operatorname{Ln}(\mathrm{L})_{3}\right]^{3+} \log K_{3}}
\end{gathered}
$$

In all experiments the mathematical best model for the data involved four absorbing $\left(\mathrm{L},[\mathrm{LnL}]^{3+},\left[\mathrm{LnL}_{2}\right]^{3+},\left[\mathrm{LnL}_{3}\right]^{3+}\right)$ and one non-absorbing $\left(\mathrm{Ln}^{3+}\right)$ species. For $\mathrm{La}$ and $\mathrm{Eu}, \log K_{2}$ and $\log K_{3}$ were independently determined by NMR titrations (low solubility of the "free" ligand prevented determination of log $K_{1}$ by this technique). Taking into account an estimated error of $\pm 10-15 \%$ on the integration of the signals, the values obtained by the latter technique are in reasonable agreement with the results obtained by spectrophotometric titration (Table 1). We observe for both terpy and $\mathrm{L}^{1}$ a decrease in the overall stability constant $\log \beta_{3}$ in going from small to large lanthanide centres. The increased electrostatic attraction of the harder cations appears to be more important here than steric hindrance, while an opposite behaviour was reported for triple helical complexes with related mbzimpy ligands. ${ }^{17}$ Given the electron donating nature of the $t$-butyl groups and based on recent calculations for complexes with substituted pyridines in the gas phase, ${ }^{18}$ the stability constants for $\mathrm{L}^{1}$ and a given lanthanide centre were expected to be larger than for analogous complexes with unsubstituted terpy. Experimentally, however, both sets of stability constants $\log \beta_{3}$ are the same within experimental error and we conclude that either the electronic and steric effects compensate each other or that the theoretical results obtained for the gas phase cannot easily be transferred to solutions.

\section{Cyclic voltammetry}

As described in an earlier report, ${ }^{13}$ we resorted to cyclic voltammetry to gain information about the relative energy of the LMCT states. Assuming that the reorganisation and solvation energies are similar for the different complexes, the difference $\Delta E$ between the half peak potentials for ligand oxidation and europium(III) reduction is proportional to the energy difference between the HOMO and LUMO orbitals and consequently reflects the relative energies of the LMCT states. The voltammograms show quasi reversible behaviour for the reduction and re-oxidation of $\mathrm{Eu}^{\mathrm{III}}$. For both $\left[\mathrm{Eu}\left(\mathrm{L}^{i}\right)_{3}\right]\left[\mathrm{ClO}_{4}\right]_{3}(i=1$ or 2$) \mathrm{com}-$ plexes the half peak potential for the $\mathrm{Eu}^{\mathrm{III}}-\mathrm{Eu}^{\mathrm{II}}$ reduction is shifted to considerably more cathodic values with respect to $\left[\mathrm{Eu}(\text { terpy })_{3}\right]\left[\mathrm{ClO}_{4}\right]_{3}$. It is tempting to see in the increasing cathodic shift from unsubstituted terpy $(-0.28 \mathrm{~V})$ over $\mathrm{L}^{2}$ $(-0.60 \mathrm{~V})$ to $\mathrm{L}^{1}(-1.05 \mathrm{~V})$ a reflection of the increasing inductive effect of the substituents. However, no substantial difference in dipole moments is reported for ethyl- and tert-butylsubstituted pyridines $(\mu=2.2,2.6-3.0$, and 2.6-2.7 $\mathrm{D}$ for pyridine, 4-ethylpyridine, and 4-tert-butylpyridine, respectively $\left.{ }^{19,20}\right)$. Using Nernst's relationship, one can estimate $\log \left\{\beta_{3}\right.$ $\left.\mathrm{Eu}^{\mathrm{III}} / \beta_{3} \mathrm{Eu}^{\mathrm{II}}\right\}$ for both triple helical complexes with respect to the solvated ion $\left[\mathrm{Eu}\left(\mathrm{NCCH}_{3}\right)_{n}\right]^{3+}$. The values obtained $\left(\mathrm{L}^{1}: 19.7\right.$ and $\left.\mathrm{L}^{2}: 12.5\right)$ compared to terpy $(7.1)^{13}$ reveal that the introduction of alkyl substituents gives rise to a strong preference for the + III state over the + II state. We note that the results obtained with $\mathrm{L}^{1}$ are almost identical to those reported previously for the rigidified $3,3^{\prime} ; 5^{\prime}, 3^{\prime \prime}$-bis(dimethylene)-2, $2^{\prime} ; 6^{\prime}, 2^{\prime \prime}$-terpyridine (dmterpy). ${ }^{13}$

The first oxidation wave is highly irreversible in both $\left[\mathrm{Eu}\left(\mathrm{L}^{i}\right)_{3}\right]\left[\mathrm{ClO}_{4}\right]_{3}(i=1$ or 2$)$ complexes and the "free" ligands. For this reason, only the peak potentials for the first forward scans are reported in Table 2. The loss of any observable signal in subsequent scans is indicative for the formation of a deposit layer on the electrode surface, which we attribute to the decomposition of the complex. Unlike in terpy and dmterpy, ${ }^{13}$ no clear-cut effect is seen between the observed oxidation peak potential of the "free" and "complexed" ligands. This could be an effect of "free" ligand present in equilibrium that is 
Table 2 Half peak $\left(E_{\mathrm{p} / 2}\right)$ and peak $\left(E_{\mathrm{p}}\right)$ potentials $v s$. SCE for europium(III) reduction and ligand oxidation ${ }^{a}$

\begin{tabular}{llcll}
\hline Compound & $\mathrm{Eu}^{\mathrm{III}}-\mathrm{Eu}^{\mathrm{II}} E_{\mathrm{p} / 2} / \mathrm{V}$ & $\log \left\{\beta_{3} \mathrm{Eu}^{\mathrm{III}} / \beta_{3} \mathrm{Eu}^{\mathrm{II}}\right\}^{b}$ & $\mathrm{~L} \longrightarrow \mathrm{L}^{+}+\mathrm{e}^{-} E_{\mathrm{p}} / \mathrm{V}$ & $\Delta E / \mathrm{V}$ \\
\hline terpy $^{c}$ & - & - & 2.02 & - \\
$\mathrm{L}^{1}$ & - & - & 2.06 & - \\
$\mathrm{L}^{2}$ & - & - & 2.24 & - \\
$\mathrm{Eu}\left(\mathrm{ClO}_{4}\right)_{3}{ }^{d}$ & +0.14 & 7.1 & 2.54 & 2.82 \\
{$\left[\mathrm{Eu}(\mathrm{terpy})_{3}\right]^{3+c}$} & -0.28 & 19.7 & 2.25 & 3.27 \\
{$\left[\mathrm{Eu}(\mathrm{dmterpy})_{3}\right]^{3+c}$} & -1.02 & 20.2 & 2.12 & 3.17 \\
{$\left[\mathrm{Eu}\left(\mathrm{L}^{1}\right)_{3}\right]^{3+}$} & -1.05 & 12.5 & 2.19 & 2.79
\end{tabular}

${ }^{a}$ Complexes $10^{-3} \mathrm{M}$, ligands as saturated solutions in anhydrous $\mathrm{MeCN}$ with $0.1 \mathrm{M} \mathrm{Et}_{4} \mathrm{NClO}_{4} \cdot{ }^{b} \approx\left[E_{\mathrm{p} / 2}\right.$ (solvate) $-E_{\mathrm{p} / 2}$ (complex) $] / 0.059 .{ }^{c} \mathrm{Ref} 13$. ${ }^{d}$ Ref. 56.

Table 3 Energy of the singlet and triplet states, phosphorescence lifetimes and intensity of the singlet $v s$. triplet ligand centred emission for the "free" ligands and their complexes with $\mathrm{La}^{\text {III } a}$

\begin{tabular}{|c|c|c|c|c|c|c|}
\hline Compound & $c / \mathrm{M}$ & $T / \mathrm{K}$ & $E\left({ }^{1} \pi \pi^{*}\right)^{b} / \mathrm{cm}^{-1}$ & $E\left({ }^{3} \pi \pi^{*}\right)^{b} / \mathrm{cm}^{-1}$ & $\tau_{\mathrm{p}} / \mathrm{ms}$ & $I\left({ }^{3} \pi \pi^{*}\right): I\left({ }^{1} \pi \pi^{*}\right)$ \\
\hline \multirow[t]{4}{*}{ terpy } & $10^{-5 c}$ & 298 & $\begin{array}{l}28388^{d} \\
27285\end{array}$ & & & \\
\hline & & 77 & $31397^{d}$ & $22962^{d}$ & \multicolumn{2}{|l|}{2100} \\
\hline & $5.5 \times 10^{-6}$ & 298 & 29240 & e & & \\
\hline & $6.7 \times 10^{-4 f}$ & 77 & 27174 & $\begin{array}{l}22727^{d} \\
21277\end{array}$ & $935(2)$ & $0.007: 1$ \\
\hline \multirow[t]{2}{*}{$\mathrm{L}^{1}$} & $6.5 \times 10^{-6}$ & 298 & 29412 & & & \\
\hline & $5.3 \times 10^{-4 f}$ & 77 & $\begin{array}{l}30769^{d} \\
29851\end{array}$ & $\begin{array}{l}22727^{d} \\
21186\end{array}$ & $748(2)$ & $0.16: 1$ \\
\hline \multirow[t]{2}{*}{$\mathrm{L}^{2}$} & $6.9 \times 10^{-6}$ & 298 & 29674 & e & & \\
\hline & $4.5 \times 10^{-4 f}$ & 77 & $\begin{array}{l}29851^{d} \\
27778\end{array}$ & $\begin{array}{l}22676^{d} \\
21368\end{array}$ & $931(2)$ & $0.16: 1$ \\
\hline \multirow{2}{*}[\mathrm{La}(\text{terpy})_{3}]{$^{3+}$} & $1.0 \times 10^{-3}$ & 298 & $26667^{d}$ & & & \\
\hline & & 77 & 26178 & $\begin{array}{l}21231^{d} \\
20041\end{array}$ & $141(1)$ & $0.020: 1$ \\
\hline$\left[\mathrm{La}\left(\mathrm{L}^{1}\right)_{3}\right]^{3+}$ & $9.1 \times 10^{-4}$ & $\begin{array}{r}298 \\
77\end{array}$ & $\begin{array}{l}26882 \\
27778^{d} \\
27174\end{array}$ & $22173^{d}$ & $169(6)$ & $0.11: 1$ \\
\hline$\left[\mathrm{La}\left(\mathrm{L}^{2}\right)_{3}\right]^{3+}$ & $9.6 \times 10^{-4}$ & $\begin{array}{r}298 \\
77\end{array}$ & $\begin{array}{l}26247^{g} \\
27322^{d} \\
26316\end{array}$ & $\begin{array}{l}21413^{d} \\
20243\end{array}$ & 181(1) & $0.27: 1$ \\
\hline
\end{tabular}

${ }^{a}$ In degassed and anhydrous MeCN. ${ }^{b}$ Maximum of the band envelope. ${ }^{c}$ In EtOH solution, ref. $21 .{ }^{d} 0-0$ transition. ${ }^{e}$ Too weak to be measured. ${ }^{f}$ In degassed and anhydrous $\mathrm{CH}_{2} \mathrm{Cl}_{2} .{ }^{g} \mathrm{~A}$ second band at $22800 \mathrm{~cm}^{-1}$ is tentatively assigned to the formation of an excimer (see text).

decomposed at the lowest potential and covers the electrode, effectively preventing observation of the oxidation of "complexed" ligand molecules. The ligand oxidation wave for both complexes $\left[\mathrm{Eu}\left(\mathrm{L}^{i}\right)_{3}\right]\left[\mathrm{ClO}_{4}\right]_{3}(i=1$ or 2$)$ appears at comparable potentials so that the observed difference $\Delta E$ (Table 2) arises solely from the different ease of europium(III) reduction. Values for $\Delta E$ are comparable to those found for the triple helical complexes with terpy (for $\mathrm{L}^{2}$ ) and dmterpy (for $\mathrm{L}^{1}$ ), respectively. ${ }^{13}$ As in these compounds, our results indicate a high energy of the LMCT states in $\left[\mathrm{Eu}\left(\mathrm{L}^{i}\right)_{3}\right]\left[\mathrm{ClO}_{4}\right]_{3}(i=1$ or 2$)$. So contrary to the observation made for the related 2,6-bis(benzimidazolyl)pyridine ligand family, non-radiative deactivation of the excited ligand centred triplet state by an LMCT pathway is predicted to be of only minor importance in our systems.

\section{Ligand centred luminescence}

The luminescence properties of terpy and its mono- and diprotonated forms have thoroughly been examined in several earlier reports. ${ }^{15,21-24}$ For the sake of comparison, we reexamined the photophysical properties of free terpy under the same experimental conditions as for $\mathrm{L}^{1}$ and $\mathrm{L}^{2}$. The results as well as those for the complexes with $\mathrm{La}^{\mathrm{III}}$ are listed in Table 3 . At room temperature in $\mathrm{MeCN}$ solution excitation of the ligands in one of their two absorption bands at $c a .35700$ and $41700 \mathrm{~cm}^{-1}$ yields one broad unresolved fluorescence band centred around $29400 \mathrm{~cm}^{-1}$. No emission from the triplet state is observable. Lanthanum(III) complexes also display one band, shifted by $2500-3500 \mathrm{~cm}^{-1}$ to lower energy, except the complex with $\mathrm{L}^{2}$ which, in addition, displays a low-lying fluorescence band around $22800 \mathrm{~cm}^{-1}$. The intensity of the latter band is heavily dependent on the excitation energy, decreasing with increasing $\tilde{v}_{\text {exc }}$ (see Supporting Information), so that we tentatively assign it as arising from an excimer. The quantum yields of the ligand-centred fluorescence are low for all three ligands and complexation to $\mathrm{La}^{\mathrm{III}}$ does not much alter these values (Table 4).

More structured fluorescence bands are seen at $77 \mathrm{~K}$ in frozen dichloromethane solutions of the "free" ligands (Fig. 1a) which display a hypsochromic shift upon alkyl substitution of the pyridines. Moreover, a broad structured phosphorescence band is also observed with a maximum around $21300 \mathrm{~cm}^{-1}$, the general shape of which is almost the same for all samples. Upon complexation to $\mathrm{La}^{\mathrm{III}}$, both the fluorescence and phosphorescence bands shift to smaller energy (Fig. 1b). The maximum of the ligand fluorescence is lowered by ca. 1000, 2700 and 1500 $\mathrm{cm}^{-1}$ for terpy, $\mathrm{L}^{1}$ and $\mathrm{L}^{2}$, respectively. The ligand ${ }^{3} \pi \pi^{*}$ state also undergoes a shift to lower energy, by approx. 1200 (terpy), $350\left(\mathrm{~L}^{1}\right)$ and $1100 \mathrm{~cm}^{-1}\left(\mathrm{~L}^{2}\right)$. In conclusion, substitution at the 4 position of the pyridinic rings induces a hypsochromic shift of the ${ }^{1} \pi \pi^{*}$ ligand state which increases with the bulkiness of the substituent while it affects less the energy of the ${ }^{3} \pi \pi^{*}$ state. Complexation to $\mathrm{La}^{\mathrm{III}}$ induces a moderate energy shift of the singlet state towards lower energy, which also increases with the bulkiness of the substituent, while the energy of the triplet state follows a comparable, but less systematic trend. 
Table 4 Absolute quantum yields of the ligand-, $\mathrm{Eu}^{\mathrm{III}}$ - and $\mathrm{Tb}^{\mathrm{III}}$ centred luminescence ${ }^{a}$

\begin{tabular}{|c|c|c|c|c|}
\hline Compound & $c / \mathrm{M}$ & $\tilde{v}_{\text {exc }} / \mathrm{cm}^{-1}$ & $\begin{array}{l}\varepsilon\left(\tilde{v}_{\text {exc }}\right) / \\
\mathrm{M}^{-1} \mathrm{~cm}^{-1}\end{array}$ & $Q$ \\
\hline \multirow[t]{2}{*}{ terpy } & $10^{-5 b}$ & - & - & $0.04^{b}$ \\
\hline & $5.5 \times 10^{-6}$ & 33223 & 9310 & 0.02 \\
\hline $\mathrm{L}^{1}$ & $6.5 \times 10^{-6}$ & 34014 & 7692 & 0.02 \\
\hline $\mathrm{L}^{2}$ & $6.9 \times 10^{-6}$ & 32468 & 8140 & 0.01 \\
\hline$\left[\mathrm{La}(\text { terpy })_{3}\right]^{3+}$ & $1.0 \times 10^{-3}$ & 27624 & 360 & 0.01 \\
\hline$\left[\mathrm{La}\left(\mathrm{L}^{1}\right)_{3}\right]^{3+}$ & $9.1 \times 10^{-4}$ & 28329 & 335 & 0.025 \\
\hline$\left[\mathrm{La}\left(\mathrm{L}^{2}\right)_{3}\right]^{3+}$ & $9.2 \times 10^{-4}$ & 27701 & 480 & $0.01^{c}$ \\
\hline$\left[\mathrm{Eu}(\text { terpy })_{3}\right]^{3+}$ & $1.0 \times 10^{-3}$ & 24155 & 51 & $0.013^{\circ}$ \\
\hline$\left[\mathrm{Eu}\left(\mathrm{L}^{1}\right)_{3}\right]^{3+}$ & $8.9 \times 10^{-4}$ & 26954 & 58 & 0.10 \\
\hline$\left[\mathrm{Eu}\left(\mathrm{L}^{2}\right)_{3}\right]^{3+}$ & $1.1 \times 10^{-3}$ & 25840 & 46 & 0.11 \\
\hline$\left[\mathrm{Tb}(\text { terpy) })_{3}\right]^{3+}$ & $1.0 \times 10^{-3}$ & 24752 & 49 & $0.047^{e}$ \\
\hline$\left[\mathrm{Tb}\left(\mathrm{L}^{1}\right)_{3}\right]^{3+}$ & $9.3 \times 10^{-4}$ & 27027 & 53 & 0.67 \\
\hline$\left[\mathrm{Tb}\left(\mathrm{L}^{2}\right)_{3}\right]^{3+}$ & $1.1 \times 10^{-3}$ & 26316 & 46 & 0.34 \\
\hline
\end{tabular}

${ }^{a}$ Solutions in anhydrous and degassed $\mathrm{MeCN}$ at $295 \mathrm{~K}^{.}{ }^{b} 300 \mathrm{~K}, \mathrm{MeCN}$ solution, referenced to 2,6-diphenylpyridine, ref. $21 .{ }^{c}$ Emission at 381 $\mathrm{nm}$ only, see text for details. ${ }^{d}$ Ref. $56 .{ }^{e}$ Ref. 57.

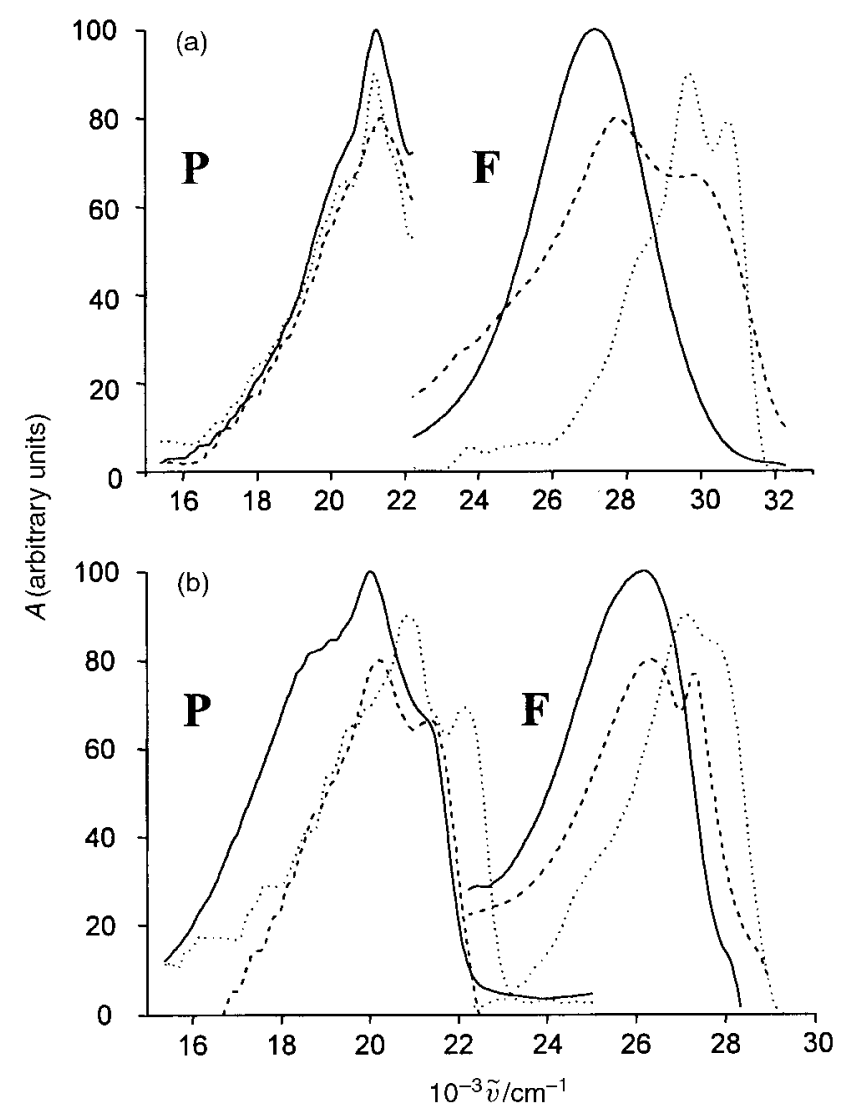

Fig. 1 Fluorescence $\mathbf{F}$ and phosphorescence $\mathbf{P}$ emission at $77 \mathrm{~K}$ of frozen solutions in dry and degassed (a) $\mathrm{CH}_{2} \mathrm{Cl}_{2}$, approx. $5 \times 10^{-4} \mathrm{M}$, $\lambda_{\text {exc }}=280 \mathrm{~nm}$ ( - terpy, $\cdots . . . \mathrm{L}^{1}$ and $\left.---\mathrm{L}^{2}\right)$, (b) MeCN, approx $1 \times 10^{-3} \mathrm{M}\left[\mathrm{La}(\text { terpy })_{3}\right]\left[\mathrm{ClO}_{4}\right]_{3}, \lambda_{\mathrm{exc}}=335 \mathrm{~nm}(\longrightarrow),\left[\mathrm{La}\left(\mathrm{L}^{1}\right)_{3}\right]\left[\mathrm{ClO}_{4}\right]_{3}$, $\lambda_{\text {exc }}=310 \mathrm{~nm}(\cdots \cdots)$ and $\left[\mathrm{La}\left(\mathrm{L}^{2}\right)_{3}\right]\left[\mathrm{ClO}_{4}\right]_{3}, \lambda_{\text {exc }}=320 \mathrm{~nm}(---)$.

Lifetimes for the phosphorescence of "free" ligands and lanthanum(III) complexes in frozen solutions are reported in Table 3. For free terpy in $\mathrm{CH}_{2} \mathrm{Cl}_{2}$ we obtain a shorter value than that reported in the literature for an $\mathrm{EtOH}$ solution. ${ }^{21}$ This difference seems to be mostly a solvent and not a concentration effect, since measurements of terpy solutions $1 \times 10^{-5}$ and $1 \times 10^{-3} \mathrm{M}$ in $\mathrm{CH}_{2} \mathrm{Cl}_{2}$ give lifetimes in the same range $(900$ $1000 \mathrm{~ms}$, vs. $2100 \mathrm{~ms}$ in EtOH). Complexation to LaIII leads to an approx. fivefold shorter lifetime of the ligand-centred phosphorescence for all three ligands, a fact we assign to the heavy atom effect, as observed for instance in porphyrin systems..$^{25,26}$ The large spin-orbit coupling of the lanthanide centre facili- tates non-radiative deactivation from the excited triplet state to $\mathrm{S}_{0}$. An approx. $20 \%$ shorter lifetime is observed for [La(terpy) $)_{3}$ ]$\left[\mathrm{ClO}_{4}\right]_{3}$ with respect to $\left[\mathrm{La}\left(\mathrm{L}^{i}\right)_{3}\right]\left[\mathrm{ClO}_{4}\right]_{3}(i=1$ or 2$)$. A likely explanation is that the alkyl substituents in $\mathrm{L}^{1}$ and $\mathrm{L}^{2}$ lower the rate of non-radiative processes by hindering the access of solvent molecules.

To get a better understanding of the energy transfer processes occurring in the triple helical complexes, we have determined the intensity ratio between the triplet and singlet state emissions for both the "free" ligands and their lanthanum(III) complexes at $77 \mathrm{~K}$ (Table 3). The phosphorescence intensity was measured under the same experimental conditions as the fluorescence intensity, except for the application of a short delay $(0.05 \mathrm{~ms})$ necessary to deactivate completely the emission from the singlet state and taking the average of five individual flashes. For free terpy, the phosphorescence accounts for only $0.7 \%$ of the intensity emitted by fluorescence while the ratio $I\left({ }^{3} \pi \pi^{*}\right): I\left({ }^{1} \pi \pi^{*}\right)$ is approx. 23 times larger for $\mathrm{L}^{1}$ and $\mathrm{L}^{2}$, reaching a total of $16 \%$. For the lanthanum(III) complexes the ratio amounts to $2 \%$ for terpy but is 5.5 and 13.5 times larger for $\mathrm{L}^{1}$ and $\mathrm{L}^{2}$, respectively. We note that the phosphorescence is enhanced upon complexation for terpy and $\mathrm{L}^{2}$, whereas it is slightly reduced for $\mathrm{L}^{1}$. Remarkable is the large increase in $I\left({ }^{3} \pi \pi^{*}\right): I\left({ }^{1} \pi \pi^{*}\right)$ observed both for the "free" ligands and the complexes upon substitution of the 4 positions. This effect can in principle arise from (i) a larger intersystem crossing (isc) population rate $k_{\text {isc }}$ or (ii) less effective deactivation processes. The latter argument is not sustained by the lifetime data: $\tau\left({ }^{3} \pi \pi^{*}\right)$ for the "free" ligands as well as for the lanthanum(III) complexes is comparable for terpy and $\mathrm{L}^{i}(i=1$ or 2$)$, the largest variation being around $30 \%$ only. We therefore conclude that the large enhancement observed in the $I\left({ }^{3} \pi \pi^{*}\right): I\left({ }^{1} \pi \pi^{*}\right)$ ratio mainly reflects an increased $k_{\text {isc }}$ in the substituted ligands and their lanthanum(III) complexes.

Why then has a seemingly small alteration at the 4 position of a pyridine ring such a profound effect on the photophysical properties? Several research groups have studied absorption and emission properties of pyridine and oligopyridines and one essential point appears to be the presence of relatively closelying $\mathrm{n} \pi^{*}$ and $\pi \pi^{*}$ states which can be coupled vibronically (proximity effect). ${ }^{27}$ The model compound pyridine is virtually non-luminescent. Very efficient non-radiative processes exist for both the lowest singlet state $\left(\mathrm{S}_{1}\right)$ and the lowest triplet state $\left(T_{1}\right)$, which is of mixed character of strongly coupled $n \pi^{*}$ and $\pi \pi^{*}$ states. ${ }^{28}$ Therefore, in parallel to weak fluorescence and although efficient isc was measured $\left(\eta_{\text {isc }}=0.9\right.$ in cyclohexane $){ }^{29}$ the phosphorescence is very weak. The photophysics of $2,2^{\prime}-$ bipyridine has been studied in various solvents and time domains. ${ }^{30-33}$ As in pyridine, the isc from $S_{1}$ to $T_{1}$ is very efficient $\left(\eta_{\text {isc }}=0.83\right.$ in cyclohexane) ${ }^{32}$ The lowest triplet state here is of $\pi \pi^{*}$ character and less efficient non-radiative pathways exist, which lead to an appreciable phosphorescence intensity. Castellucci et al. $^{34}$ have found a large influence of methyl substituents on the intersystem crossing process in monomeric and dimeric bipyridine systems. Dimeric bipyridines containing alkyl substituents in both the 4 and 5 positions display nonradiative deactivation rates of $S_{1} 7.5$ times larger than for 2,2'bipy. The next homologue, terpy, has also been the subject of several studies, ${ }^{15,21-24}$ but to our knowledge no determination of the population efficiency of $T_{1}$ and the nature (n $\pi^{*}$ or $\left.\pi \pi^{*}\right)$ of this state has been reported. Compared to 2,2'-bipy, isc from $S_{1}$ to $T_{1}$ seems to be considerably less efficient in terpy. As a consequence, terpy displays an appreciable fluorescence quantum yield. $\left(Q^{\mathrm{F}}=0.04\right.$ in $\left.\mathrm{MeCN}\right){ }^{21}$ Protonation has a strong influence on the photophysical properties of pyridine and the oligopyridines. This is on the one hand the consequence of conformational changes (e.g. terpy from trans-trans to ciscis), on the other to the change of the overall charge. An impressive increase in fluorescence quantum yield $\left(Q^{\mathrm{F}}=0.61\right.$ in $0.2 \mathrm{M} \mathrm{H}_{2} \mathrm{SO}_{4}$ vs. $Q^{\mathrm{F}}=0.04$ in $\mathrm{MeCN}$ ) was reported for terpy. ${ }^{21}$ 
In conclusion, we assign the profound influence on the photophysical properties of terpy upon substitution at the 4 positions reported above to changes in the coupling of energetically close lying $\mathrm{n} \pi^{*}$ and $\pi \pi^{*}$ states.

\section{Metal-centred luminescence}

Upon UV irradiation, solutions of $\left[\mathrm{Ln}\left(\mathrm{L}^{i}\right)_{3}\right]\left[\mathrm{ClO}_{4}\right]_{3}(\mathrm{Ln}=\mathrm{Eu}$ or $\mathrm{Tb} ; i=1$ or 2 ) strongly emit light in the characteristic red for $\mathrm{Eu}^{\mathrm{III}}$ and green region for $\mathrm{Tb}^{\mathrm{III}}$, respectively. The quantum yields of the metal centred emission of the complexes upon ligand excitation are listed in Table 4 . The complexes of $\mathrm{L}^{1}$ and $\mathrm{L}^{2}$ with $\mathrm{Eu} \mathrm{u}^{\mathrm{III}}$ are approximately 9 times stronger emitters than the analogous terpy compound, confirming that de-excitation through an energy path involving a LMCT state is not operative (see section on cyclic voltammetry). The increase within the terbium(III) series is even more pronounced with a gain factor in quantum yields of $10\left(\mathrm{~L}^{2}\right)$ and $15\left(\mathrm{~L}^{1}\right)$, respectively. With an absolute quantum yield in the range of $50-70 \%$, these compounds are among the most efficient emitters in solution reported, being comparable for instance with 2,6-bis(pyrazolyl)pyridine $\left(Q^{\mathrm{Tb}}=0.84 \text { in water }\right)^{35}$ or tetraazatriphenylene $\left(Q^{\mathrm{Tb}}=0.62 \text { in } \mathrm{MeCN}\right)^{36}$ complexes. Interestingly, $\mathrm{L}^{i}(i=1$ or 2$)$ are both good antennae for $\mathrm{Tb}^{\mathrm{III}}$ and $\mathrm{Eu}^{\mathrm{III}}$, which is often not the case for other classes of sensitiser molecules where energy transfer is efficient towards only one and not the other central cation due to the energy of the donor triplet state of the ligand. The quantum yield of lanthanide-centred luminescence can be expressed by ${ }^{5}$ eqn. (4) where $\eta_{\text {isc }}$ stands for the intersystem

$$
Q^{\mathrm{Ln}}=\eta_{\text {isc }} \eta_{\mathrm{et}} k_{\mathrm{r}}^{0} / k_{\mathrm{obs}}
$$

crossing efficiency of the antenna, $\eta_{\text {et }}$ for that of the energy transfer step, while $k_{\mathrm{r}}^{0}$ and $k_{\mathrm{obs}}=1 / \tau_{\mathrm{obs}}$ are the radiative and observed rate constants, respectively. Several considerations have to be made to determine to which extent each parameter influences the overall quantum yield. Steemers et al. ${ }^{7}$ defined energetic conditions for efficient antenna molecules for lanthanide-centred emission. On the one hand, the energy gap between the $0-0$ transitions of the lowest singlet and triplet state of the ligand should be at least $5000 \mathrm{~cm}^{-1}$ to generate sizable $\eta_{\text {isc }}$. For efficient energy transfer to the luminescent excited state of the lanthanide ion $\left(\eta_{\mathrm{et}}\right)$, the ligand triplet state should be at least $3500 \mathrm{~cm}^{-1}$ more energetic. On the other hand, energy back transfer from $\mathrm{Tb}^{\mathrm{III}}$ to the ligand, a temperaturedependent non-radiative deactivation mode affecting $k_{\text {obs }}$, may be observed. Latva et al. ${ }^{8}$ conclude from their array of complexes with substituted pyridines that to prevent such a process at ambient temperature the lowest triplet state of the ligand should be at least $1850 \mathrm{~cm}^{-1}$ above the ${ }^{5} \mathrm{D}_{4}$ level. For Eu${ }^{\mathrm{III}}$, the energy transfer to the upper ${ }^{5} \mathrm{D}_{J}$ levels $(J=1-3)$ seems to be most efficient when the ligand triplet state is approximately 500 $\mathrm{cm}^{-1}$ more energetic than the specific acceptor level concerned; excitation energy is then transferred to the ${ }^{5} \mathrm{D}_{0}$ level that is the predominant emitting state. ${ }^{8}$ The ligand singlet-triplet gap, taken as the difference between the most energetic emission features identified in the emission spectra of the triple helical lanthanum(III) complexes studied here (Table 3), amounts to 4950, 5600 and $5900 \mathrm{~cm}^{-1}$ for terpy, $\mathrm{L}^{1}$ and $\mathrm{L}^{2}$, respectively. These values are over or in the range of the lower limit of 5000 $\mathrm{cm}^{-1}$ as defined above and thus on energetic grounds the $\eta_{\text {isc }}$ should be large. Looking at the energy of the ligand triplet states in the lanthanum(III) complexes, one can conclude that an energy transfer to the metal ions is only feasible to the ${ }^{5} \mathrm{D}_{J}$ $(J=0-2)$ levels of $\mathrm{Eu}^{\mathrm{III}}$ and the ${ }^{5} \mathrm{D}_{4}$ level of $\mathrm{Tb}^{\mathrm{III}}$. For the energy transfer to $\mathrm{Eu}^{\mathrm{III}}$, the energy gaps between the triplet and the ${ }^{5} \mathrm{D}_{0}$ (3900-4800 $\left.\mathrm{cm}^{-1}\right)$ and ${ }^{5} \mathrm{D}_{1}\left(2300-3200 \mathrm{~cm}^{-1}\right)$ levels are in the range of the optimum value of $3500 \mathrm{~cm}^{-1}$ proposed by Steemers et $a l^{7}$ For energy transfer to $\mathrm{Tb}^{\mathrm{III}}$ the energy gap is in all cases below the threshold value of $1850 \mathrm{~cm}^{-1}$ : we measure a
Table 5 Lifetime of the metal-centred emission in the complexes of $\mathrm{Eu}^{\mathrm{III}}$ and $\mathrm{Tb}^{\mathrm{III}}$ in anhydrous MeCN solutions upon ligand excitation at $295 \mathrm{~K}$

\begin{tabular}{llll}
\hline Compound & $c / \mathrm{M}$ & $\tilde{v}_{\text {exc }} / \mathrm{cm}^{-1}$ & $\tau_{\mathrm{p}} / \mathrm{ms}$ \\
\hline$\left[\mathrm{Eu}(\text { terpy })_{3}\right]^{3+}$ & $1.0 \times 10^{-3}$ & 27027 & $2.31(1)$ \\
{$\left[\mathrm{Eu}\left(\mathrm{L}^{1}\right)_{3}\right]^{3+}$} & $1.2 \times 10^{-3}$ & 28169 & $2.14(2)$ \\
{$\left[\mathrm{Eu}\left(\mathrm{L}^{2}\right)_{3}\right]^{3+}$} & $1.1 \times 10^{-3}$ & 27397 & $2.60(3)$ \\
{$\left[\mathrm{Tb}(\mathrm{terpy})_{3}\right]^{3+}$} & $1.0 \times 10^{-3}$ & 27397 & $1.20(1)$ \\
{$\left[\mathrm{Tb}\left(\mathrm{L}^{1}\right)_{3}\right]^{3+}$} & $9.3 \times 10^{-4}$ & 27933 & $1.33(2)$ \\
& $a$ & 32468 & $1.16(1)$ \\
{$\left[\mathrm{Tb}\left(\mathrm{L}^{2}\right)_{3}\right]^{3+}$} & $1.1 \times 10^{-3}$ & 32468 & $1.38(1)$ \\
& $b$ & 27027 & $1.64(2)$
\end{tabular}

${ }^{a}$ Solid sample, laser excitation, $295 \mathrm{~K} .{ }^{b}$ Solid sample, laser excitation, $20 \mathrm{~K}$.

difference of 830,1770 and $1010 \mathrm{~cm}^{-1}$ for terpy, $\mathrm{L}^{1}$ and $\mathrm{L}^{2}$, respectively. Even with these low energy gaps, no large increase in the lifetime of the metal-centred emission is observed when the temperature is lowered to $20 \mathrm{~K}$ (solid state, see Table 5). Thermal energy back transfer, as observed for instance for terbium(III) cryptates, ${ }^{10}$ seems therefore to be of minor importance in $\left[\mathrm{Tb}\left(\mathrm{L}^{i}\right)_{3}\right]^{3+}(i=1$ or 2$)$. We note, however, that the ${ }^{5} \mathrm{D}_{4}$ lifetimes are shorter (1.2-1.6 ms, cf. Table 5) than the $\operatorname{Eu}\left({ }^{5} \mathrm{D}_{0}\right)$ lifetimes. The latter are longer than $2 \mathrm{~ms}$ and point to a metal ion well protected from solvent access and free of deactivating water molecules in the first co-ordination sphere, confirming vibrational data. The increase observed between the complexes with terpy and $\mathrm{L}^{2}$ (about 15\%) reflects less non-radiative deactivation processes in the latter complex but cannot explain the more than 8 -fold increase in the quantum yield. Partial ligand decomplexation may result in an increase of metal centred luminescence as shown for europium(III) complexes of substituted 2,6-bis(benzimidazol-2-yl)pyridine ${ }^{37}$ or benzoate ${ }^{38}$ ligands. However, the determined stability constants point to less than $10 \%\left[\operatorname{Ln}(\text { terpy })_{2}\right]^{3+}$ and less than $20 \%\left[\operatorname{Ln}\left(\mathrm{L}^{1}\right)_{2}\right]^{3+}$ in the measured $1 \times 10^{-3} \mathrm{M}$ solutions. We therefore assume that such a process is unlikely to account for the large difference observed in the quantum yields.

The influence of electron donating and accepting substituents on the intensity of emission of $\mathrm{Eu}^{\mathrm{III}}$ and $\mathrm{Tb}^{\mathrm{III}}$ has been studied for $\beta$-diketonates. ${ }^{39,40}$ Electron withdrawing substituents on phenyl groups decrease the luminescence intensity, while electron donating substituents induce either an increase or no effect at all. Enhanced intersystem crossing was found for $p$-methoxy compared to $m$-methoxy substituents in the gadolinium(III) complexes. In a related study on ligands with $\mathrm{N}$-donors, Sinha ${ }^{41}$ reported that 4,4'-dimethyl-2,2'-bipyridine (dm 2,2'-bipy) enhances the metal-centred luminescence 1.9 times compared to 2,2'-bipyridine in solid $\left[\mathrm{Eu}(\mathrm{L})_{2}\right] \mathrm{Cl}_{3} \cdot 2 \mathrm{H}_{2} \mathrm{O}$ ( $\mathrm{L}=2,2^{\prime}$-bipy or dm $2,2^{\prime}$-bipy). In $\left[\mathrm{Tb}(\mathrm{L})_{2}\right]\left[\mathrm{NO}_{3}\right]_{3} \cdot 2 \mathrm{H}_{2} \mathrm{O}$ complexes the methyl substituted ligand leads to a 1.2 times increased luminescence intensity. Better energy transfer from the ligand sphere to the lanthanide centre upon introduction of the methyl substituents was advanced as rationalisation for these observations. As detailed in the paragraph on ligandcentred luminescence, alkyl substitution at the 4 position of the pyridine ring leads to a dramatic increase of the population of the ligand triplet state. We therefore assign the increase in quantum yields for the complexes with $\mathrm{L}^{i}(i=1$ or 2$)$ as mainly due to this effect. Taking into account the short lifetimes measured for the terbium(III) complexes, the energy transfer from the ligand sphere has to be very efficient to lead to the impressive quantum yields observed. The middle values for $Q^{\mathrm{Eu}}$ combined with the long lifetime of emission in the europium(III) complexes point to a less efficient energy transfer than in the related terbium(III) compounds. The increase in lanthanide-centred emission upon substitution of the pyridine 4 position is much bigger than in the systems reported by Sinha. ${ }^{41}$ Besides that we have worked 


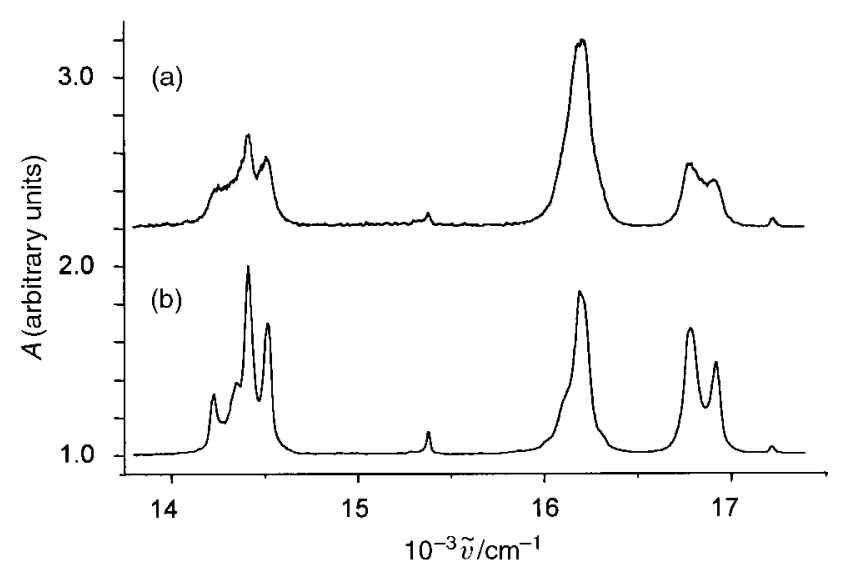

Fig. 2 Emission spectra of approx. $1 \times 10^{-3} \mathrm{M}$ solutions in dry and degassed $\mathrm{MeCN}$ at $295 \mathrm{~K}$. (a) $\left[\mathrm{Eu}\left(\mathrm{L}^{1}\right)_{3}\right]\left[\mathrm{ClO}_{4}\right]_{3}, \lambda_{\text {exc }}=352 \mathrm{~nm}$. (b) $\left[\mathrm{Eu}\left(\mathrm{L}^{2}\right)_{3}\right]\left[\mathrm{ClO}_{4}\right]_{3}, \lambda_{\text {exc }}=359 \mathrm{~nm}$.

under perfectly anhydrous conditions, we relate this to the facts that (i) three tridentate ligands completely saturate the first lanthanide(III) co-ordination sphere, preventing deactivation by anions and water molecules, and (ii) the ethyl and tert-butyl substituents we introduced on the pyridine rings are bulkier than methyl groups and induce both more conformational changes and more electronic effects.

High resolution luminescence measurements on the europium(III) complexes with $L^{1}$ and $L^{2}$

The emission spectra of approx. $1 \times 10^{-3} \mathrm{M}$ solutions of $\left[\mathrm{Eu}\left(\mathrm{L}^{i}\right)_{3}\right]\left[\mathrm{ClO}_{4}\right]_{3}(i=1$ or 2$)$ in $\mathrm{MeCN}$ at ambient temperature are depicted in Fig. 2. The overall band shape and intensity of the individual transitions are very similar in both complexes. The only exception is the ${ }^{5} \mathrm{D}_{0} \longrightarrow{ }^{7} \mathrm{~F}_{2}$ transition that is twice as intense with $\mathrm{L}^{1}$ than for $\mathrm{L}^{2}$. The number of components observed for the ${ }^{5} \mathrm{D}_{0} \longrightarrow{ }^{7} \mathrm{~F}_{J}(J=1-4)$ transitions point to low symmetries of the emitting europium(III) sites. ${ }^{42}$ For $\left[\mathrm{Eu}\left(\mathrm{L}^{2}\right)_{3}\right]-$ $\left[\mathrm{ClO}_{4}\right]_{3}$ the asymmetry and broadness of the weak ${ }^{5} \mathrm{D}_{0} \longrightarrow{ }^{7} \mathrm{~F}_{0}$ transition is indicative of more than one emitting site. This is confirmed by selective laser excitation at the low- and highenergy side of the transition leading to different intensities of the two components of the ${ }^{5} \mathrm{D}_{0} \longrightarrow{ }^{7} \mathrm{~F}_{1}$ transition and to a shift of its maxima. The nature of the putative two sites is difficult to pin down. It may well be that, as for [Eu(terpy) $\left.{ }_{3}\right]$ $\left[\mathrm{ClO}_{4}\right]_{3}$ in the solid state, ${ }^{43}$ a species involving co-ordinated $\mathrm{MeCN}$ and a species without solvent in the first co-ordination sphere co-exist in equilibrium.

\section{Conclusion}

The introduction of alkyl substituents in the 4 positions of terpyridine, particularly tert-butyl, leads to ligands which display considerably enhanced sensitisation efficiency for luminescence of $\mathrm{Eu}^{\mathrm{III}}$ and $\mathrm{Tb}^{\mathrm{III}}$ compared to unsubstituted terpyridine. In particular, large quantum yields have been obtained for $\mathrm{Tb}^{\mathrm{III}}$ in acetonitrile. The observed dramatic effect of a seemingly small addition to the ligand framework illustrates the difficulty in predicting lanthanide luminescence efficiencies solely from the energy of the lowest ligand centred triplet state. Other factors, including the population rate of this state by intersystem crossing processes, may even be more influential. We have shown here that the population of the ligand triplet state can dramatically be altered by simple modification of the ligand framework. The systems we describe are sensitive to hydrolysis and water interaction and cannot directly be used in biomedical applications. However, taking advantage of the effects evidenced in this work in other ligand families better suited for labelling techniques, such as for instance 2,2'bipyridine $6,6^{\prime}$-dicarboxylic acid, ${ }^{44}$ seems to be feasible.

\section{Experimental}

\section{Syntheses and characterisations}

Acetonitrile (Fluka for UV spectroscopy) was degassed by three consecutive freeze-pump-thaw cycles and dried over $3 \AA$ molecular sieves. Lanthanide perchlorates and triflates were prepared from the oxides (Rhône-Poulenc, 99.99\%) and dried according to published procedures. ${ }^{45,46}$ The lanthanide contents of the solutions and the solid salts was determined by complexometric titration vs. xylene orange. ${ }^{47} \mathrm{Et}_{4} \mathrm{NClO}_{4}$ (Fluka, purum) was purified and dried as described earlier. ${ }^{13}$ $\left[\mathrm{Ln}(\text { terpy })_{3}\right]\left[\mathrm{ClO}_{4}\right]_{3}(\mathrm{Ln}=\mathrm{La}, \mathrm{Eu}$ or $\mathrm{Tb})$ were synthesized following the original preparation of Durham et al. ${ }^{48}$ and dried following the same procedures as for the lanthanide perchlorates. $2,2^{\prime}: 6^{\prime}, 2^{\prime \prime}$-Terpyridine (Fluka) was sublimed twice under vacuum; 4, $4^{\prime}, 4^{\prime \prime}$-tri-tert-butyl-2,2';6', $6^{\prime \prime}$-terpyridine $\left(\mathrm{L}^{1}\right)$ was prepared according to the literature ${ }^{49}$ and $4,4^{\prime}, 4^{\prime \prime}$-triethyl$2,2^{\prime} ; 6^{\prime}, 2^{\prime \prime}$-terpyridine $\left(\mathrm{L}^{2}\right)$ kindly donated by Peter Péchy and K. Kalyanasundaram, Institute of Photonics and Interfaces, Swiss Federal Institute of Technology, Lausanne, Switzerland. Other chemicals were purchased from Fluka (Buchs, Switzerland) or Acros (Geel, Belgium) and used as received.

Complexes $\left[\mathrm{Ln}\left(\mathrm{L}^{1}\right)_{3}\right]\left[\mathrm{ClO}_{4}\right]_{3}(\mathrm{Ln}=\mathrm{La}, \mathrm{Eu}$ or $\mathrm{Tb})$ were prepared from the respective perchlorate salts $\mathrm{Ln}\left(\mathrm{ClO}_{4}\right)_{3} \cdot n \mathrm{H}_{2} \mathrm{O}$ $(n=3-5)$. In a typical procedure, $\mathrm{L}^{1}\left(21.6 \mathrm{mg}, 5.4 \times 10^{-5} \mathrm{~mol}\right)$ dissolved in EtOH (1 mL) was added slowly under nitrogen to a refluxing solution of $\mathrm{Eu}\left(\mathrm{ClO}_{4}\right)_{3} \cdot 3.50 \mathrm{H}_{2} \mathrm{O}$ in EtOH $(1 \mathrm{~mL})$. Reflux was maintained for $2 \mathrm{~h}$, then the reaction mixture was evaporated to dryness. The residue was dissolved in 3 portions of $\mathrm{MeCN}(1 \mathrm{~mL})$, filtered and after removal of the solvent dried for $48 \mathrm{~h}\left(40^{\circ} \mathrm{C} / 2 \times 10^{-2} \mathrm{mbar}\right)$. Yields of the off-white residues: $89(\mathrm{La}), 86(\mathrm{Eu})$ and 90\% (Tb). $\left[\mathrm{La}\left(\mathrm{L}^{1}\right)_{3}\right]\left[\mathrm{ClO}_{4}\right]_{3}: v\left(\mathrm{ClO}_{4}\right) 1086$ and $623 \mathrm{~cm}^{-1}\left(\mathrm{KBr}\right.$ pellet); $\delta_{\mathrm{H}}\left(360 \mathrm{MHz}, \mathrm{CD}_{3} \mathrm{CN}\right) 8.17(\mathrm{~s}, 2 \mathrm{H})$, $8.03(\mathrm{~d}, 2 \mathrm{H}, J=1.2), 7.93(\mathrm{~d}, 2 \mathrm{H}, J=5.6), 7.10(\mathrm{~d} \times \mathrm{d}, 2 \mathrm{H}$, $J=1.9,5.6 \mathrm{~Hz}), 1.56(\mathrm{~s}, 9 \mathrm{H})$ and $1.31(\mathrm{~s}, 18 \mathrm{H})$; ES mass spectrum $(\mathrm{MeCN}) \mathrm{m} / \mathrm{z} 1139.4\left\{\left(\left[\mathrm{La}\left(\mathrm{L}^{1}\right)_{2}\right]\left(\mathrm{ClO}_{4}\right)_{2}\right)^{+}, 90\right\}, 720.9$ $\left.\left\{\left[\mathrm{La}\left(\mathrm{L}^{1}\right)_{3}\right]\left(\mathrm{ClO}_{4}\right)\right)^{2+}, 100\right\}$ and $447.6\left\{\left[\mathrm{La}\left(\mathrm{L}^{1}\right)_{3}\right]^{3+}, 55 \%\right\}$ (Found: C, 57.8; $\mathrm{H}, 7.3 ; \mathrm{N}, 7.0$. Calc. for $\left.\left[\mathrm{La}\left(\mathrm{L}^{1}\right)_{3}\right]\left[\mathrm{ClO}_{4}\right)\right]_{3} \cdot 4 \mathrm{EtOH} \cdot \mathrm{H}_{2} \mathrm{O}$ : $\mathrm{C}, 57.4 ; \mathrm{H}, 7.2 ; \mathrm{N}, 6.8 \%$. [Eu( $\left.\left(\mathrm{L}^{1}\right)_{3}\right]\left[\mathrm{ClO}_{4}\right]_{3}: v\left(\mathrm{ClO}_{4}\right) 1085$ and 621 $\mathrm{cm}^{-1}(\mathrm{KBr}$ pellet $) ; \delta_{\mathrm{H}}\left(360 \mathrm{MHz}, \mathrm{CD}_{3} \mathrm{CN}\right) 16.34(\mathrm{~s}, 2 \mathrm{H}), 6.12(\mathrm{~s}$, $\mathrm{H}), 2.49(\mathrm{~s}, 2 \mathrm{H}), 2.09(\mathrm{~s}, 2 \mathrm{H}), 0.82(\mathrm{~s}, 18 \mathrm{H})$ and $0.46(\mathrm{~s}, 9 \mathrm{H})$; ES mass spectrum $(\mathrm{MeCN}) \mathrm{m} / z 1155.4\left\{\left(\left[\mathrm{Eu}\left(\mathrm{L}^{1}\right)_{2}\right]\left(\mathrm{ClO}_{4}\right)_{2}\right)^{+}\right.$, $100\}$ and $452.3\left\{\left[\mathrm{Eu}\left(\mathrm{L}^{1}\right)_{3}\right]^{3+}, 20\right\}$. $\left[\mathrm{Tb}\left(\mathrm{L}^{1}\right)_{3}\right]\left[\mathrm{ClO}_{4}\right]_{3}: v\left(\mathrm{ClO}_{4}\right) 1095$ and $622 \mathrm{~cm}^{-1}$ (KBr pellet); ES mass spectrum $(\mathrm{MeCN}) \mathrm{m} / \mathrm{z}$ $1562.7\left\{\left(\left[\mathrm{~Tb}\left(\mathrm{~L}^{1}\right)_{3}\right]\left(\mathrm{ClO}_{4}\right)_{2}\right)^{+}, 20\right\}, 1159.4\left\{\left(\left[\mathrm{~Tb}\left(\mathrm{~L}^{1}\right)_{2}\right]\left(\mathrm{ClO}_{4}\right)_{2}\right)^{+}\right.$, $\left.80\}, 730.9\left(\left[\mathrm{~Tb}\left(\mathrm{~L}^{1}\right)_{3}\right]\left(\mathrm{ClO}_{4}\right)\right)^{2+}, 100\right\}$ and $454.3\left\{\left[\mathrm{~Tb}\left(\mathrm{~L}^{1}\right)_{3}\right]^{3+}, 20\right\}$.

Complexes $\left[\mathrm{Ln}\left(\mathrm{L}^{2}\right)_{3}\right]\left[\mathrm{ClO}_{4}\right]_{3}(\mathrm{Ln}=\mathrm{La}, \mathrm{Eu}$ or $\mathrm{Tb})$ were prepared in situ by dissolving three equivalents of solid $\mathrm{L}^{2}$ in stock solutions of $\mathrm{Ln}\left(\mathrm{ClO}_{4}\right)_{3}$ in dry and degassed $\mathrm{MeCN}$ containing exactly one equivalent of metal and equilibrated for at least $24 \mathrm{~h}$ at ambient temperatures before measurements.

CAUTION: dry perchlorate salts may explode and should be handled only in small quantities and with appropriate precautions.

\section{Physicochemical measurements}

Electronic spectra were measured using a Perkin-Elmer Lambda 7 UV/VIS spectrophotometer. Luminescence spectra, quantum yields and lifetimes determinations were recorded on a Perkin-Elmer LS-50 spectrometer. The reported lifetimes are averages of at least five determinations. In all cases, no significant improved fit was observed for a bi-exponential decay model. Reproducibility of independent determinations of the intensity ratio between the triplet and singlet state emissions at $77 \mathrm{~K}$ was always better than $15 \%$. The instrumental set-up for high-resolution luminescence spectra and lifetime determinations was described earlier. ${ }^{50}$ Quantum yields for the ligandcentred luminescence were measured relative to quinine sulfate in $0.05 \mathrm{M} \mathrm{H}_{2} \mathrm{SO}_{4} \quad\left(A_{347}=0.05\right.$; absolute quantum yield $=$ 
0.546). ${ }^{51}$ Concentrations of the "free" ligand solutions were chosen so that the absorbance was $A=0.05$ at the maximum of the lowest energy absorption band. Quantum yields of the lanthanum(III) complexes were determined at several excitation wavelengths with absorbance $A=0.3-0.5$ relative to quinine sulfate solutions displaying comparable absorbance at $347 \mathrm{~nm}$ Concentrations of the complexes were $1 \times 10^{-3} \mathrm{M}$ to avoid problems of decomplexation ${ }^{13}$ and for $\left[\mathrm{La}\left(\mathrm{L}^{2}\right)_{3}\right]\left[\mathrm{ClO}_{4}\right]_{3}$ only the high-energy emission band was taken into account. Quantum yields for the metal centred emission of the complexes of $\mathrm{Eu}$ and $\mathrm{Tb}$ were determined relative to solutions of the respective $\left[\mathrm{Ln}(\text { terpy })_{3}\right]\left[\mathrm{ClO}_{4}\right]_{3}$ complexes at $10^{-3} \mathrm{M}$ in dry and degassed acetonitrile as described earlier. ${ }^{13,52}$ The integrated luminescence intensity was determined on a linear energy scale $\left(\mathrm{cm}^{-1}\right)$ and to guarantee a linear relationship between the emitted light and the concentration the excitation wavelengths were chosen so that the absorbance $A \leq 0.2$.

${ }^{1} \mathrm{H}$ NMR spectra ( $\delta$ with reference to TMS) were recorded on Bruker AM-360 and DRX Avance 400 spectrometers, in $\mathrm{CD}_{3} \mathrm{CN}$ dried over $\mathrm{CaH}_{2}$. The EI-MS data were collected on a Bruker FTMS BioAPEX II spectrometer at the University of Fribourg, Switzerland. Reported are the peaks with maximum intensity of the isotopic envelope. Dr H. Eder (Microchemical Laboratory, University of Geneva, Switzerland) performed elemental analysis. The IR spectra were measured on a Mattson Alpha Centauri FT spectrometer as $\mathrm{KBr}$ pellets.

Cyclic voltammograms were recorded in a micro cell on an $\mathrm{EG}+\mathrm{G}$ Potentiostat 263A. All acetonitrile solutions contained $0.1 \mathrm{M}$ dry $\mathrm{Et}_{4} \mathrm{NClO}_{4}$ as inert electrolyte. The standard three electrode set-up comprised a glassy carbon $(\mathrm{EG}+\mathrm{G}$ 60229) working electrode, a platinum $(\mathrm{EG}+\mathrm{G} \mathrm{K} 0266)$ counter electrode and a $\mathrm{Ag}-\mathrm{AgCl}(\mathrm{EG}+\mathrm{G} \mathrm{K} 0265)$ reference electrode. $\left[\mathrm{Ru}\left(2,2^{\prime} \text {-bipy }\right)_{3}\right]\left[\mathrm{ClO}_{4}\right]_{3}$ was used as standard, taking its oxidation potential as $+1260 \mathrm{mV} v s$. SCE. ${ }^{53}$

\section{Stability constant determinations}

Electronic spectra for spectrophotometric titrations were recorded at $20^{\circ} \mathrm{C}$ on a Perkin-Elmer Lambda 7 spectrometer in $0.1 \mathrm{~cm}$ quartz cells. All solutions were in dry acetonitrile and contained $0.1 \mathrm{M}$ dry $\mathrm{Et}_{4} \mathrm{NClO}_{4}$ as inert electrolyte. In a typical experiment, $15 \mathrm{~mL}$ of $10^{-4} \mathrm{M}$ ligand solution were titrated with $10^{-3} \mathrm{M} \mathrm{Ln}^{\mathrm{III}}\left(\mathrm{ClO}_{4}\right)_{3}$ at $25^{\circ} \mathrm{C}$ in a thermostatted vessel in a glove box. After each addition of metal solution the mixture was equilibrated for $15 \mathrm{~min}$ before the UV-vis spectrum of an aliquot was measured outside the glove box. After re-introduction into the box the next metal addition took place. Overall 30 spectra with $30 \leq[\mathrm{L}] /[\mathrm{M}] \geq 0.2$ were recorded each and treated by evolving factor analysis using the SPECFIT software package. $^{54}$ The water content of the solution was checked before and after the measurements by Karl Fischer titrations and never exceeded $50 \mathrm{ppm}$.

${ }^{1} \mathrm{H}$ NMR spectra for the determination of stability constants by NMR titration were recorded in $\mathrm{CD}_{3} \mathrm{CN}$ (dried over $\mathrm{CaH}_{2}$ ) at $25^{\circ} \mathrm{C}$ on a Bruker AM-360 spectrometer. In a typical experiment, at least five solutions with $3.5 \leq[\mathrm{L}] /[\mathrm{M}] \geq 1$ were prepared. Stock solutions of the ligand (in $\mathrm{CH}_{2} \mathrm{Cl}_{2}$ ) and the lanthanide (in $\mathrm{CH}_{3} \mathrm{CN}$ ) were mixed, evaporated to dryness and re-dissolved in $0.4 \mathrm{~mL}$ dry $\mathrm{CD}_{3} \mathrm{CN}$ in a glove box to give $c(\mathrm{Ln})_{\mathrm{tot}} \approx 1 \times 10^{-3} \mathrm{M}$. Stability constants were extracted from the integrated surfaces of selected signals using the MINEQL ${ }^{+}$ program. ${ }^{55}$ Owing to the low solubility of the "free" ligands in acetonitrile, the values for $\log K_{1}$ obtained by spectrophotometric titrations were used in the fitting model.

\section{Acknowledgements}

We gratefully acknowledge the technical assistance in high resolution measurements of Ms. V. Foiret, the services of the MS facility at the University of Fribourg (Switzerland),
Professor A. Merbach, University of Lausanne (Switzerland) for access to the electrochemical equipment and P. Péchy and K. Kalyanasundaram, Swiss Federal Institute of Technology, Lausanne (Switzerland) for the donation of a sample of $\mathrm{L}^{2}$. This work is supported through grants from the Swiss National Science Foundation and the U.S. National Science Foundation (CHE-9714998 to RPT).

\section{References}

1 C. H. Evans, Biochemistry of the Lanthanides, Plenum Press, New York, 1990.

2 I. Hemmilä, T. Stahlberg and P. Mottram, Bioanalytical Applications of Labelling Technologies, Wallac Oy, Turku, 1995.

3 G. Mathis, in Rare Earths, eds. R. Saez Puche and P. Caro, Editorial Complutense, Madrid, 1998, p. $285 f f$.

4 D. Parker, P. K. Senanayake and J. A. G. Williams, J. Chem. Soc., Perkin Trans. 2, 1998, 2129.

5 N. Sabbatini, M. Guardigli and I. Manet, in Handbook on the Physics and Chemistry of Rare Earths, eds. K. A. J. Gschneidner and L. Eyring, Elsevier, Amsterdam, 1996, vol. 23, ch. 154.

6 O. L. Malta, J. Luminesc., 1997, 71, 229.

7 F. J. Steemers, W. Verboom, D. N. Reinhoudt, E. B. Vandertol and J. W. Verhoeven, J. Am. Chem. Soc., 1995, 117, 9408.

8 M. Latva, H. Takalo, V. M. Mukkala, C. Matachescu, J.-C. Rodriguez-Ubis and J. Kankare, J. Luminesc., 1997, 75, 149.

9 A. Beeby, I. M. Clarkson, R. S. Dickins, S. Faulkner, D. Parker, L. Royle, A. S. de Sousa, J. A. G. Williams and M. Woods, J. Chem. Soc., Perkin Trans. 2, 1999, 493.

10 B. Alpha, R. Ballardini, V. Balzani, J.-M. Lehn, S. Perathoner and N. Sabbatini, J. Photochem. Photobiol., 1990, 52, 299.

11 J.-C. G. Bünzli and F. Ihringer, Inorg. Chim. Acta, 1996, 246, 195.

12 G. Blasse, Mater. Chem. Phys., 1992, 31, 3.

13 S. Petoud, J. C. G. Bünzli, T. Glanzman, C. Piguet, Q. Xiang and R. P. Thummel, J. Luminesc., 1999, 82, 69.

14 R. D. Chapman, R. T. Loda, J. P. Riehl and R. W. Schwartz, Inorg. Chem., 1984, 23, 1652.

15 M. G. B. Drew, M. J. Hudson, P. B. Iveson, M. L. Russell, J. O. Liljenzin, M. Skalberg, L. Spjuth and C. Madic, J. Chem. Soc., Dalton Trans., 1998, 2973.

16 C. Mallet, R. P. Thummel and C. Hery, Inorg. Chim. Acta, 1993, 210, 223.

17 S. Petoud, J. C. G. Bunzli, F. Renaud, C. Piguet, K. J. Schenk and G. Hopfgartner, Inorg. Chem., 1997, 36, 5750.

18 F. Berny, N. Muzet, L. Troxler, A. Dedieu and G. Wipff, Inorg. Chem., 1999, 38, 1244.

19 CRC Handbook of Chemistry and Physics, ed. D. R. Lide, CRC Press, Boca Raton, FL, 1996.

20 Beilstein Database update BS9904PR, Beilstein Informationssysteme GmbH, Frankfurt, 2000.

21 A. Sarkar and S. Chakravorti, J. Luminesc., 1995, 63, 143.

22 D. W. Fink and W. E. Ohnesorge, J. Phys. Chem., 1970, 74, 72.

23 A. Fernandez Gutirrez, M. Roman Ceba, A. Munoz de la Pena and S. G. Schulman, J. Fluoresc., 1996, 6, 97.

24 K. Nakamoto, J. Phys. Chem., 1960, 64, 1420.

25 L. Flamigni, F. Barigelletti, N. Armaroli, B. Ventura, J. P. Collin, J. P. Sauvage and J. A. G. Williams, Inorg. Chem., 1999, 38, 661.

26 A. Prodi, M. T. Indelli, C. J. Kleverlaan, F. Scandola, E. Alessio, T. Gianferrara and L. G. Marzilli, Chem. Eur. J., 1999, 5, 2668.

27 E. C. Lim, in Excited States, ed. E. C. Lim, Academic Press, New York, 1982, vol. 3, p. 305ff.

28 S. Tero-Kubota, K. Akiyama, T. Ikoma and Y. Ikegami, J. Phys. Chem., 1991, 95, 766.

29 M. Terazima and T. Azumi, Chem. Phys. Lett., 1988, 153, 27.

30 G. Buntinx, R. Naskrecki and O. Poizat, J. Phys. Chem., 1996, 100, 19380.

31 E. Castellucci, L. Angeloni, G. Marconi, E. Venturi and I. Baraldi, J. Phys. Chem., 1990, 94, 1740.

32 R. D. Saini, S. Dhanya and P. K. Bhattacharyya, J. Photochem. Photobiol., 1988, 43A, 91.

33 G. Marconi, L. Angeloni, E. Castellucci and M. C. Migliorini, Méd. Biol. Environ., 1995, 23, 58.

34 E. Castellucci, L. Angeloni, A. Juris, G. Marconi and R. Ziessel, J. Photochem. Photobiol. A, 1992, 67, 311.

35 M. J. Remuinan, H. Roman, M. T. Alonso and J.-C. RodriguezUbis, J. Chem. Soc., Perkin Trans. 2, 1993, 1099.

36 E. B. Vandertol, H. J. Vanramesdonk, J. W. Verhoeven, F. J. Steemers, E. G. Kerver, W. Verboom and D. N. Reinhoudt, Chem. Eur. J., 1998, 4, 2315. 
37 C. Piguet, J. C. G. Bünzli, G. Bernardinelli, C. G. Bochet and P. Froidevaux, J. Chem. Soc., Dalton Trans., 1995, 83.

38 W. Schrott, H. Büchner and U. Steiner, J. Inf. Recording, 1996, 23, 79.

39 F. Filipescu, W. F. Sager and F. A. Serafin, J. Phys. Chem., 1964, 68 3324.

40 W. F. Sager, N. Filipescu and F. A. Serafin, J. Phys. Chem., 1965, 69, 1092.

41 S. P. Sinha, J. Inorg. Nucl. Chem., 1966, 28, 189.

42 J. C. G. Bünzli, in Lanthanide Probes in Life, Chemical and Earth Sciences. Theory and Practice, eds. J.-C. G. Bünzli and G. R Choppin, Elsevier, Amsterdam, 1989, p. $240 \mathrm{ff}$.

43 L. I. Semenova, A. N. Sobolev, B. W. Skelton and A. H. White, Aust. J. Chem., 1999, 52, 519.

44 L. J. Charbonnière, J.-C. G. Bünzli and R. Ziessel, J. Chem. Soc., Dalton Trans., 2000, 1917.

45 J. F. Desreux, in Lanthanide Probes in Life, Chemical and Earth Sciences. Theory and Practice, eds. J.-C. G. Bünzli and G. R. Choppin, Elsevier Science Publ. B. V., Amsterdam, 1989, p. $43 \mathrm{ff}$. 46 J.-C. G. Bünzli and F. Pilloud, Inorg. Chem., 1989, 28, 2638.
47 G. Schwarzenbach, Complexometric Titrations, Chapman \& Hall, London, 1957.

48 D. A. Durham, G. H. Frost and F. A. Hart, J. Inorg. Nucl. Chem., 1969, 31, 833 .

49 T. B. Hadda and H. L. Bozec, Polyhedron, 1988, 7, 575.

50 J.-C. G. Bünzli and A. Milicic-Tang, Inorg. Chim. Acta, 1996, 252, 221.

51 S. R. Meech and D. C. Phillips, J. Photochem., 1983, 23, 193.

52 L. Le Saulnier, S. Varbanov, R. Scopelliti, M. Elhabiri and J. C. G. Bünzli, J. Chem. Soc., Dalton Trans., 1999, 3919.

53 A. Juris, V. Balzani, P. Belser and A. v. Zelewsky, Helv. Chim. Acta, 1981, 64, 2175.

54 SPECFIT, version 2.11, Spectrum Software Asociates, Chapel Hill, NC, 1993.

55 MINEQL+, version 3.01b, Environmental Research Software, Hallowell, ME, 1989.

56 S. Petoud, J. C. G. Bünzli, K. J. Schenk and C. Piguet, Inorg. Chem., 1997, 36, 1345.

57 F. Renaud, C. Piguet, G. Bernardinelli, J. C. G. Bünzli and G. Hopfgartner, Chem. Eur. J., 1997, 3, 1646. 